\title{
O ABUSO SEXUAL INFANTIL SOBRE O PRISMA DA OBRA “O MISTÉRIO DAS BONECAS DE PORCELANA"1
}

\author{
Ana Paula Barbosa Teixeira ${ }^{2}$, Centro Universitário Santo Agostinho UNIFSA
}

\section{RESUMO}

O presente trabalho visa analisar juridicamente auxiliado pela Literatura, o abuso sexual infantil bem como as consequências trazidas por este, tendo como guia o caso de Beatriz, na obra "O mistério das bonecas de porcelana" de Eneas Barros. Dessa forma, para que os objetivos e metas propostos fossem alcançados. Utilizamos como metodologia a pesquisa bibliográfica de natureza qualitativa tendo como abordagem o método Dedutivo. Para a classificação e ressignificação dos dados da pesquisa foram realizadas leituras de livros, artigos, doutrinas e jurisprudências, culminando com a análise e interpretação dos dados pesquisados. Foram utilizados como aportes teóricos estudos de autores/as como: Barros (2015), Azevedo e Guerra (1997), Trindade (2010), Dias (2006), o Estatuto da Criança e do Adolescente e o Código Penal Brasileiro, dentre outros/as com o propósito de identificar como o meio jurídico com suas leis positivadas fornecem amparo à criança e adolescente, vítimas de abusos e que tais ações resultam em penas aos infratores; e ainda como a Literatura diante de suas obras aliadas ao Direito foi capaz de mostrar por meio da ficção o pesadelo vivido por uma criança abusada sexualmente tornando-se a Literatura dessa forma, um meio eficaz para a reflexão daqueles que se debruçam no mundo das leis.

Palavras-Chave: Direito e Literatura. Abuso Sexual Infantil. O Mistério das Bonecas de Porcelana.

\section{INTRODUÇÃO}

Muitos são os debates e teorias que surgem e se difundem sobre a violência com moldes de abuso sexual infantil. São pesquisas de vários campos do conhecimento como Psicologia, Direito, Educação, Sociologia, História, Antropologia, dentre outras ciências, configurando-se, assim, como um tema complexo, interdisciplinar e dinâmico visto que reflete em todos os âmbitos em que está inserido o sujeito passivo. Dessa forma, a temática abuso sexual infantil vem progressivamente sendo discutida por muitos estudiosos como Faleiros (2000), Trindade (2010), Silva (2013) dentre

\footnotetext{
${ }^{1}$ Trabalho apresentado no Congresso Brasileiro Ciência e Sociedade (CBCS 2019), promovido pelo Centro Universitário Santo Agostinho, de 03 a 05 de outubro de 2019, em Teresina-PI.

${ }^{2}$ Acadêmica do Curso de Direito do Centro Universitário Santo Agostinho - UNIFSA.E-mail: ani_paula02@hotmail.com
} 


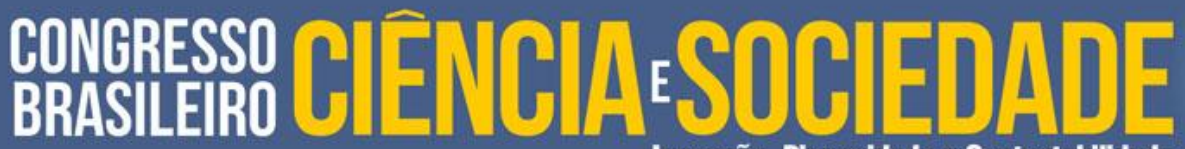

ANAIS CBCS 2019 | 3 a 5 de outubro de 2019 | Centro Universitário Santo Agostinho - Teresina - PI

outros/as, que também a classificam como complexa, necessitando de uma abordagem também interdisciplinar a ser investigada.

Dessa forma, a presente pesquisa surgi como inquietação de uma professora que muitas vezes ver o sofrimento de crianças vítimas de abuso, tendo assim a pesquisa como objetivo geral analisar juridicamente o abuso sexual infantil apresentado na obra "O mistério das bonecas de porcelana" sobre o prisma do Estatuto da Criança e do Adolescente. Como objetivos específicos revisar a bibliografia sobre o abuso sexual infantil; bem como discutir juridicamente o abuso sexual infantil demonstrado na obra "O mistério das bonecas de porcelana".

Para que os objetivos fossem alcançados, a pesquisa foi realizada no período de agosto de 2018 a junho de 2019 por meio de um estudo bibliográfico que fez uso principal da obra "O mistério das bonecas de porcelana" atrelando a esta obras e legislação que pudessem ajudar na ressignificação da temática em pauta.

\section{METODOLOGIA}

O presente artigo foi construído com base na pesquisa bibliográfica e para uma melhor concretização da pesquisa está teve como abordagem o Método Dedutivo

A classificação dos dados da pesquisa foi realizada com o auxílio de livros, artigos, doutrinas e jurisprudências. Para isso, foram estes pesquisados em base de dados Scielo, periódicos caps e google acadêmico, sobre abuso sexual infantil, violência intrafamiliar e análise do livro "O mistério das bonecas de porcelana" de Eneas Barros fazendo uma relação entre a temática, a obra e a legislação vigente. Com o fim de alcançar os objetivos propostos a pesquisa foi realizada no período de Agosto de 2018 e Junho de 2019

\section{DIREITO E LITERATURA}

\subsection{Direito e Literatura: Um diálogo interdisciplinar}


ANAIS CBCS 2019 | 3 a 5 de outubro de 2019 | Centro Universitário Santo Agostinho - Teresina - PI

Frequente são os questionamentos acerca da existência de um entrelaçamento de direito e literatura. Em que momento de suas existências estas se cruzam a ponto de fazer um casamento perfeito? Qual o grau de contribuição essa interdisciplinaridade pode trazer ao Direito?

Tentando sanar tais dúvidas faz-se necessário entender que a literatura a partir de seus escritos é capaz de abrir uma lacuna subjetiva em relação ao outro que admite uma maior aproximação e sensibilização com outras faces da mesma realidade.

Ao passo que tratamos com indiferença os problemas físicos e sociais, a literatura em meio ao seu mundo das artes ao qual participa, faz uso da compaixão e da solidariedade ao próximo (MORIN, 2000, p. 98). Agindo assim, a Literatura deixa como legado ao mundo jurídico a sua abordagem como movimento interdisciplinar, ao permitir a transformação do Direito como meio de emancipação política.

Neste sentido, Trindade e Gubert (2008, p. 12) reconhecem que

a possibilidade da aproximação dos campos jurídico e literário favorece ao direito assimilar a capacidade criadora, crítica e inovadora da literatura e, assim, superar as barreiras colocadas pelo sentido comum teórico, bem como reconhecer a importância do caráter constitutivo da linguagem, destacando-se os paradigmas da intersubjetividade e intertextualidade.

Sendo assim, um diálogo prazeroso existente entre o Direito e a Literatura acaba por permitir a ampliação de conhecimentos e uma melhor compreensão do Direito positivado

\subsection{Direito e Literatura na Obra "O Mistério das Bonecas de Porcelana"}

O cenário trazido por Eneas Barros em sua narrativa desmistifica a vida de uma família tida como "perfeita" aos olhos de quem a ver, uma família tão normal, tão patriarcal, tão naturalizada, formada pelo pai, mãe e duas "queridas "filhas, ou seja, blindada de todo o mal periférico que acarreta o resto da sociedade.

Na obra, Beatriz colocada como protagonista nesse cenário de "normalidade familiar" grita pela defesa de seus direitos, direitos fundamentais estes que acabam por ser muitas vezes 


\section{CONQGEESSO CIENCIAESOCIEDADE

ANAIS CBCS 2019 | 3 a 5 de outubro de 2019 | Centro Universitário Santo Agostinho - Teresina - PI

negligenciados pelo ornamento jurídico. Diante desse palco, sonhos, desejos, esperanças, infância são deixadas de lado para dar lugar a um pesadelo que vem disfarçado de amigo, o que acaba por expor rotulagens de uma menina cheia de manias e birras.

Nesse contexto, a Literatura oferece denúncias e serve de alerta ao Direito pois este por vezes generaliza e segrega casos de abuso infantil como o sofrido por Beatriz como sendo passado apenas pelas classes menos favorecidas e esquecendo que a violência perpassa os muros não apenas das famílias segregadas, mas também ultrapassa a proteção dos jardins dos casarões.

\section{ABUSO E VIOLÊNCIA}

\subsection{A caracterização da vítima na obra}

Beatriz em sua infância exala em seus comportamentos uma criança dentro dos padrões normais de tranquilidade, saúde e que possuía um gosto enorme pela vida bem como sonhos e desejos a serem alcançados.

O cenário muda de contexto quando Beatriz é vítima de abuso. $O$ autor em seus escritos nos mostra mudanças de comportamentos e o mergulhar em um mundo de pesadelos que nunca acabam.

As luzes estavam apagadas e pouco se percebia a silhueta de Beatriz que àquela hora da noite se aproveitava de uma réstia luz do poste da rua para vislumbrar o quarto destruído por sua fúria. Passava das nove. Trajava um camisolão branco, que costumava usar para dormir. Estava recostada à parede, de tal forma que era possível, com apenas um movimento da cabeça vislumbrar a praça. (BARROS, 2015, p. 21)

As características da pessoa supracitada fogem totalmente das trazidas em outrora aquela criança cheia de sonhos que sonhava e gostava de andar elegante, dando lugar a raiva, ao descontrole, a solidão, ao pesadelo, tudo isso é capaz de mostrar claramente as consequências do abuso vivido.

Conforme Trintade (2010, p.82) o abuso sexual sofrido por uma criança ou adolescente tem a capacidade de mudar sobremaneira a personalidade da vítima, 


\section{CONQGEESOOCIENCIAESOCIEDADE

ANAIS CBCS 2019 | 3 a 5 de outubro de 2019 | Centro Universitário Santo Agostinho - Teresina - P

De fato, as consequências do abuso sexual podem ser muito diversificadas: a apresentação condutas sexualizadas, conhecimento atípico sobre sexo, sentimentos de estigmatização, isolamento, hostilidade, desconfiança, medo, baixa auto-estima, sentimentos de culpa, fracasso ou dificuldades escolares, precocidade sexual, transtorno de estresse pós-traumáticos [...]

Trazendo os fatos supracitados para o caso da Beatriz, a sua mudança repentina de comportamento, está diretamente ligada a experiência traumática que passou quando criança e que se transformando em um fardo mais pesado do que possa imaginar, que trouxe consigo o desanimo, a perda do sentido de ser feliz e sobretudo o fato de ser protagonista de um pesadelo sem fim.

\subsection{Josino: ser estranho, ladrão de infância, vítima da violência extrafamiliar}

Na obra, Josino aparece como sendo um ser estranho, porém de uma simpatia e conversas que acabam por atrair a confiança de quem cruza seu caminho.

Quem era o estranho que lhe agradava daquela forma? Somente à aquela pouca distância pôde perceber que o seu olho direito estava sempre aberto, brilhava de forma estranha [...] embora não fosse um rosto simpático, mas assustador, ela não teve receios; era amigo da família e lhe dava presentes. (BARROS, 2015, p. 31)

Na maioria dos casos que envolve abuso extrafamiliar contra crianças e adolescente o crime é praticado por alguém conhecido, pois antes de agir este, procura estabelecer uma confiança com a criança, por meio de um jogo de sedução para então depois cometer o abuso ou a violência. (FORTES, 2015, p 35).

Sanderson (2005, p.143) nos desenha os pedófilos como "predadores sexuais disfarçados de homens gentis, ou seja, lobos em pele de cordeiro". Foi justamente essa atitude realizada por Josino quando atraiu Beatriz para o escuro da mata aproveitando-se de sua inocência e confiança nutridas a ele, além das ameaças típicas entre o agressor e a criança abusada. 
ANAIS CBCS 2019 | 3 a 5 de outubro de 2019 | Centro Universitário Santo Agostinho - Teresina - P

Josino se esgueirou pela penumbra e se mostrou para a menina, que tomou um susto, mas o reconheceu de imediato. Ele colocou o dedo indicador no lábio, pedindo silêncio, e em seguida disse baixinho que não queria que as pessoas soubessem que ele estava ali. Convidou-a para ir com ele apanhar uma boneca que trouxera. Ela se levantou, pegou em sua mão e o acompanhou mata a dentro, sentindo-se segura.[...] a menina tentou esquecer a escuridão por alguns instantes, esforçando-se para não contrariá-lo. Mostrou que ela deveria se comportar. Beatriz achou estranho, mas ele era de confiança de seu pai e seu amigo, pois já havia lhe dado três bonecas [...] e assim ele fez tudo o que ele queria, satisfazendo o seu desejo doentio. (BARROS 2015, p. 89)

A realidade trazida pelos casos no dia a dia nos fazem observar o quanto a Literatura em forma de ficção casa-se com a realidade. Josino é uma figura clássica de um pedófilo que aprov eita da inocência e de certa forma do descuido familiar para a través da confiança já conquistada com Beatriz.

\subsection{Tipificação no ordenamento jurídico brasileiro}

O abuso sexual possui grandes índices, que trazem consigo sequelas por vezes irreparáveis, vários são os dispositivos legais que fazem a segurança desse individuo tentando protegê-lo do que já aconteceu ou principalmente tentando evitar o que possa ocorrer em virtude da sua vulnerabilidade.

Dessa maneira, a Constituição em seu artigo. 227 nos ensina que:

É dever da família, da sociedade e do Estado assegurar à criança, ao adolescente e ao jovem, com absoluta prioridade, o direito à vida, à saúde, à alimentação, à educação, ao lazer, à profissionalização, à cultura, à dignidade, ao respeito, à liberdade e à convivência familiar e comunitária, além de colocá-los a salvo de toda forma de negligência, discriminação, exploração, violência, crueldade e opressão.

O ordenamento nos mostra que o sujeito em formação é reconhecido como alguém que precisa de todo amparo nesse processo de desenvolvimento, tendo como principais responsáveis conforme a Carta Magna a família.

A família de Beatriz no que tange a proteção dessa fase de desenvolvimento, agiu com falhas, quando por exemplo, a mãe que caba por desistir de procurar uma resposta para o que filha 
ANAIS CBCS 2019 | 3 a 5 de outubro de 2019 | Centro Universitário Santo Agostinho - Teresina - PI

passava, "Leonor havia desistido de dar importância ao comportamento da filha.", bem como o pai que diante de sua ausência, tentava se desculpar pelo fato de estar trabalho, ao tentar pagar sua ausência com mimos dados a menina. (BARROS, 2015, p. 129)

A Constituição além de proteger o ser em formação deixando-a sob a responsabilidade da família, mas sobretudo também do estado, quando por exemplo, prevê em seu artigo. 277, no parágrafo 4으, que: “§ 4으 A lei punirá severamente o abuso, a violência e a exploração sexual da criança e do adolescente".

Eneas Barros (2015, p. 89) traz em sua obra uma verdadeira personificação do artigo 217-A do Código Penal, quando o Josino foi capaz de fazer uso da inocência da pequena Beatriz bem como de sua confiança pautada na relação advinda entre seu pai e o agressor.

Ele tinha uma noção de onde ficavam as partes menos frequentadas da fazenda, quando a visitou pela primeira vez, por isso conduziu Beatriz por caminhos pouco frequentados. [...] depois de alguns metros, a garota começou a ficar com receios e, por isso, puxava a sua mão querendo voltar. [...] a menina tentou esquecer a escuridão por alguns instantes, esforçando-se para não contrariá-lo [...] depois de abusar da menina, levou-a de volta às proximidades da casa [...].

O Estatuto da Criança e do Adolescente, como diploma legal especificamente destinado a defender os interesses destes, dispõe no artigo 5 que "[...] nenhuma criança ou adolescente será objeto de qualquer forma de negligência, discriminação, exploração, violência, crueldade e opressão, punido na forma da lei qualquer atentado, por ação ou omissão, aos seus direitos fundamentais".

O Estatuto da Criança e do Adolescente como lei especializada traz também trata também de artigos que falam da proteção ao menor com os detalhes. Tendo como destaque os artigos 13 e 136 que atuam como forma de coibir os maus tratos e incumbem de responsabilidade quem deve denunciar. Os artigos 15 ao 18, que velam pela dignidade e direito à liberdade da criança e adolescente, proibindo, inclusive maus tratos por negligência.

\subsection{Abuso e violência na obra}


ANAIS CBCS 2019 | 3 a 5 de outubro de 2019 | Centro Universitário Santo Agostinho - Teresina - PI

No decorrer da obra "O mistério das bonecas de porcelana" é possível por meio da Literatura vislumbrar condutas tipificadas, delituosas passíveis de penalidade no nosso ordenamento jurídico.

Um exemplo claro de violência intrafamiliar é a conduta praticada pela mãe Eleonor que por deveras vezes maltratou, desrespeitou, ignorou a pequena Beatriz por meio de seus castigos e ameaças de quem na verdade deveria Ihe dar carinho, segurança e proteção o que acabava por aumentar ainda mais o sofrimento e pesadelo ao qual Beatriz foi lançada, sofrendo cotidianamente pelos "[...] castigos que ela recebia da mãe, das surras, do desinteresse pelas coisas da filha e dos mimos a Augusta. Detalhou ainda o dia em Eleonor a colocou de castigo no sótão, deixando-a pior do que estava". (BARROS, 2015, p. 153)

Tem também o pai Mundico, uma pessoa a qual Beatriz nutria grande afeto, no entanto em virtude da ausência constante preenchido pelas atividades trabalhistas o fazia ser ausente a ponto de não corresponder o carinho e a segurança de que tanto a filha necessitava, a enchendo de presentes e de tudo aquilo que o dinheiro pudesse comprar.

Dessa forma, o ordenamento jurídico brasileiro, coloca em pauta na Constituição Federal em seu artigo 227 caput que perante as crianças e adolescentes e dada responsabilidades ao Estado, à sociedade em geral e particularmente à família, como meios de promover segurança e desenvolvimento saudável da criança e adolescente.

No mesmo sentido preleciona Maria Berenice Dias (2006, p. 45), veja-se:

A missão constitucional dos pais, pautada nos deveres de assistir, criar e educar os filhos menores, não se limita a vertentes patrimoniais. A essência do poder parental é a mais importante, que coloca em relevo a afetividade responsável que liga pais e filhos, propiciada pelo encontro, pelo desvelo, enfim, pela convivência familiar.

Na narrativa Eneas Barros leva os leitores a mergulhar no mundo confuso vivenciado pela protagonista que nem mesmo nos próprios pais confia pois quando precisava sair " deixava a caixa fechada e escondia a chave. Ou entregava para Mariinha, em confiança." (BARROS, p. 46). Beatriz depositava toda a confiança em Mariinha a empregada da família e quem cuidara da adolescente desde pequena "viu as meninas crescerem e ajudou Leonor a criá-las [...] era profundamente 


\section{CONWEESSOC CIENCIAESOCIEDADE

ANAIS CBCS 2019 | 3 a 5 de outubro de 2019 | Centro Universitário Santo Agostinho - Teresina - P

simpática e cativante [...] era tia que toda criança gostaria de ter, protetora [...], ou seja, Marrinha para Beatriz, preenchia um pouco do espaço que fora de certa forma abandonado pela família.

No que tange ao abuso e violência intrafamiliar sofrido por Beatriz teve como responsável o seu tio Leo, que se aproveita da fragilidade emocional da adolescente e da confiança depositada nele para abusar sexualmente da adolescente

A menina sentou-se ao lado de seu tio Leo, abrançando-o de vez enquando, com o olhar terno. [...] ansiosa por esperar: seu companheiro, aquele que a ajudava a cuidar das crianças, que lhe dava e sexo [...] o homem a visitava com regularidade, de certa forma abusando da inocência de uma adolescente perturbada [...] Era o segredo que eles tinham, uma porta fechada a que ninguém poderia ter acesso. (BARROS, p. 213 e 216).

A obra mostra que o tio de Beatriz faz uso da fragilidade emocional, carência e necessidade de afeto da adolescente para saciar seu instinto animal, fazendo-a acreditar que formariam uma família e que ele a ajudaria criar seus "filhos".

Tem-se ainda, Josino, aquele que rouba os sonhos da pequena menina que aos 7 anos de idade tem sua inocência surrupiada pelo monstro do olho de vidro "a partir daquela noite, a imagem do homem com o olho de boneca passou a um monstro que a perseguia e tirava o seu sossego, açoitando sua inocência" e que diante dos fatos o crime praticado por Josino encontra-se tipificado no artigo 217-A caput do Código Penal Brasileiro, sob a denominação de estupro de vulnerável. (BARROS, p.90)

\section{CONSEQUÊNCIAS DO ABUSO SEXUAL INFANTIL}

\subsection{As marcas do abuso sexual na vítima}

O abuso sexual infantil deixa na criança ou adolescente que sofre tal violência múltiplas e variadas consequências, que afetam o desenvolvimento físico, psíquico e social. Dessa forma, autores como (FURNISS, 2002) traz em seus escritos que o infanto-juvenil ao ser vítima do abuso sexual pode sofrer com a "síndrome do segredo", a qual traz as mais variadas consequências como 


\section{CONQGEESSO CIENCIAESOCIEDADE

ANAIS CBCS 2019 | 3 a 5 de outubro de 2019 | Centro Universitário Santo Agostinho - Teresina - PI

o sentimento de culpa, a vergonha, a dor e o medo, que surgem por meio da violência sofrida, trauma estes por vezes irreversíveis.

Na obra de Eneas Barros fica claro as consequências do abuso sofrido por Beatriz quando se ver que,

A aflição provocava-Ihe um mal-estar físico, que a deixava lesada e sem ânimo para brincar com as novas amizades que fizera no colégio, inclusive com a irmã. [...] Logo depois da mudança, os conflitos internos de Beatriz aumentaram. [...]. Ela estava mais insensível aos prazeres infantis, transferindo para as suas bonecas a alegria que não expressava. Imaginava que uma vida mais fria do que a sua, que respirava, mas não sentia o fôlego do entusiasmo.[...] no colégio era retraída. Choramingava, encolhida à cama, desejando que o sono voltasse e que não precisava viver aquelas aflições. E assim passava as noites em claro, o que a tornava irritada durante todo o dia seguinte. (BARROS, 2015, p, 121 a 123)

As consequências deixadas na vida de uma criança ou adolescente que sofre o abuso é algo imensurável a sua compreensão e avaliação, não sendo dessa forma, um trabalho fácil por não terem estudos que possam fazer tal analise através de um acompanhamento dessa vítima durante sua vida para fazer uma mensuração das consequências trazidas.

Trindade, 2010, p. 81 ao citar em sua obra Noguerol (1997) afirma em seus escritos que as consequências ou o grau de severidade dos efeitos do abuso sexual manifestam-se na forma de transtornos funcionais como:

Pesadelos, terrores noturnos, dificuldades de conciliar o sono, medo de escuro, enurese diurna /noturna, encoprese, estranhamento. Como expressão de problemas de conduta, agressão física, choro fácil, retraimento, raiva, não querer se desnudar ou tomar banho, não querer fazer ginástica e realizar desenhos sexualizados; na adolescência, fuga de casa, automutilação, consumo de drogas, roubos, antissocialidade e delinquência; como dificuldades escolares, problemas de concentração, atenção e memória, gazeteios.

Diferente das consequências supracitadas a vítima do abuso além das consequências psíquicas sofre trazendo todos esses traumas para a sua vida social refletindo em todos os outros âmbitos dos quais faça parte. 
ANAIS CBCS 2019 | 3 a 5 de outubro de 2019 | Centro Universitário Santo Agostinho - Teresina - P

\section{CONSIDERAÇÕES FINAIS}

A análise da narrativa de Eneas Barros mostra ao leitor como se dá por excelência o casamento entre Direito e Literatura, sendo essa união capaz de sensibilizar os juristas e adoradores do Direito a verem casos como o de Beatriz algo além das leis positivadas, e ver quantas "Beatrizes" existem e clamam em seu silêncio e inocência de criança por justiça e por mais sensibilidade daqueles que operam o Direito.

Conclui-se ainda que o comportamento trazido pela menina Beatriz se encaixa perfeitamente ao descrito por profissionais e pesquisadores acerca do tema Abuso sexual infantil, consequências estas físicas e psíquicas e por vezes duradouras e que tais vítimas como a protagonista da obra, a o não encontrarem a uxílio de quem mais espera que é a família, o sofrimento vivenciado diariamente multiplica-se restando apenas o seu fechamento no pesadelo.

Dessa forma, encontra-se legalmente, que o Estado, a sociedade, e, sobretudo, a família é clamada a juntar forças com o objetivo de construir em conjunto e com segurança um ambiente saudável para que crianças e adolescentes possam se desenvolver em um espaço de amor, carinho e segurança, e não apenas tentar comprar a feição destes com bens materiais como o fez Mundico e nem tentar sanar a ausência com violência com fez Leonor, muito menos aproveitar-se na inocência infantil e da confiança para sanar seus desejos ilícitos com fez tio Leo e muito pior ainda descontar o que sofrera da sociedade e comprar a amizade de uma criança e depois destruí-la com violência como fez Josino.

Mas, acima de tudo devemos construir uma relação em sociedade pautada no a mor, carinho, confiança, principalmente para com aqueles que se encontram em desenvolvimento, como as crianças e adolescentes afim de que estes possam crescer saudáveis com o auxílio da família e confiantes no Estado e na sociedade que trazem "armas" como o artigo 227, caput da Constituição Brasileira e o Estatuto da Criança e do Adolescente para ajuda-las a lutar por um mundo melhor.

\section{REFERÊNCIAS}




\section{cONQ⿻口卄ESSOCIENCIASSOCIEDADE

ANAIS CBCS 2019 | 3 a 5 de outubro de 2019 | Centro Universitário Santo Agostinho - Teresina - PI

BARROS, Eneas. O Mistério das bonecas de Porcelana. Teresina: Nova Aliança, 2015.

BRASIL. Constituição de 1988. Constituição da República Federativa do Brasil. Disponível em: . Acesso em: 08 nov. 2018

L, Estatuto da criança e do adolescente lei federal n.ㅇ 8069. Congresso Federal, 1990.

. Lei no 2.848, de 07 de dezembro de 1940. Código Penal. Disponível em: Acesso em: 20 de nov. 2018..

CUNHA, E. P.; SILVA, E. M.; GIOVANETTI, A. C. Enfrentamento à violência sexual infanto-juvenil: expansão do PAIR em Minas Gerais. Belo Horizonte: UFMG, 2008.

DIAS, Maria Berenice, Manual de Direito das Famílias, 3a edição. São Paulo: Editora Revista dos Tribunais 2006.

FALEIROS, Vicente de Paula. A violência sexual contra crianças e adolescentes e a construção de indicadores: a crítica do poder, da desigualdade e do imaginário, SER Social, n. 2, 2000.

FORTES, Casé. Todos contra a pedofilia. Belo Horizonte: Arraes Editores, 2015.

FURNISS, Tilman. Abuso sexual da criança: Uma abordagem multidisciplinar. Porto Alegre: Artmed, 2002.

MORIN, E. Os sete saberes necessários à educação do futuro. São Paulo/Brasília: Cortez/Unesco, 2000

SANDERSON, Christiane. Abuso sexual em crianças: Fortalecendo Pais e Professores Para Proteger Crianças Contra Abusos Sexuais e Pedofilia. São Paulo: M. Books, 2008.

SILVA, Lillian Ponchio. Et al. Pedofilia e Abuso Sexual de Crianças e Adolescentes. São Paulo: Ed. Saraiva, 2013.

TRINDADE, J.; BREIER, R.. Pedofilia: aspectos psicológicos e penais. 2. ed. Porto Alegre: Livraria do Advogado Editora, 2010.

TRINDADE, André Karam. GUBERT, Roberta Magalhães. Direito \& Literatura- Reflexões Teóricas. Porto Alegre, RS: Livraria do Advogado Editora, 2008 